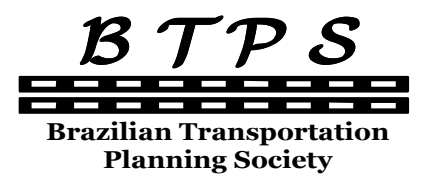

Journal of Transport Literature

Vol. 8, n. 3, pp. 37-61, Jul. 2014

Research Directory

\title{
Fatores intervenientes na relação entre a inclusão social e o trem considerando as favelas e as taxas de embarque observadas nas estações
}

[Commuter train usage considering favelas and station boarding rates]

\author{
Jorge Augusto Martins Gonçalves*, Gustavo Teixeira de Andrade, \\ Licinio da Silva Portugal
}

Federal University of Rio de Janeiro - Brazil

Submitted 6 May 2013; received in revised form 30 Sep 2013; accepted 1 Nov 2013

\begin{abstract}
Resumo
A redução da desigualdade e da exclusão social é uma preocupação mundial. No Brasil, esses temas se expressam nas favelas, isoladas espacialmente, devido à falta de sintonia entre os setores de transporte e de habitação. Um encaminhamento para a solução do problema envolve a execução de melhorias na acessibilidade, com base no maior uso do transporte público e na construção de moradias populares e na concentração de atividades no entorno de suas estações. A fim de contribuir com essa temática, o objetivo do estudo é identificar os fatores intervenientes na relação entre a população que mora em favelas e as viagens por trem. As favelas e as estações são Polos Geradores de Viagens importantes que reforçam a necessidade dessa articulação. Os fatores intervenientes que restringem/incentivam o acesso à estação apontam onde e como intervir na área de transporte. Essas propostas devem ser efetivadas por meio de políticas públicas includentes, que integrem os indivíduos aos meios sociais, estabelecendo padrões de acessibilidade nos diferentes espaços que contribuem para compatibilizar a taxa de mobilidade dos moradores das favelas com a dos demais moradores.
\end{abstract}

Palavras-Chave: inclusão social, sistema sobre trilhos, favelas, acessibilidade, imobilidade.

\begin{abstract}
Reduction of inequality and social exclusion is a global concern. In Brazil, this theme has particular bearing on residents of favelas, which are generally isolated spatially from the rest of the city because of a lack of harmony between the transportation and habitation sectors. A path toward a solution to the problem is to improve accessibility by increasing the use of public transportation, including by the construction of low-cost housing and concentration of activities near commuter train stations. This study examines the factors influencing the relationship between the people who live in favelas and their use of commuter trains. These communities and stations are important trip generation hubs, reinforcing the need for this articulation. The factors that discourage/encourage access to stations indicate how to intervene in the transportation area. These proposals need to be put into effect by inclusive public policies that seek to integrate individuals in the social milieu, by establishing standards of accessibility in different spaces that help harmonize the mobility of favela residents with that of other city dwellers.
\end{abstract}

Key words: social inclusion, rail systems, favelas, accessibility, immobility.

*Email: goncalves@pet.coppe.ufrj.br.

\section{Recommended Citation}

Gonçalves, J. A. M., Andrade, G. T. and Portugal, L. S. (2014) Fatores intervenientes na relação entre a inclusão social e o trem considerando as favelas e as taxas de embarque observadas nas estações. Journal of Transport Literature, vol. 8, n. 3, pp. 37-61.

- JTL/RELIT is a fully electronic, peer-reviewed, open access, international journal focused on emerging transport markets and published by BPTS - Brazilian Transport Planning Society. Website www.transport-literature.org. ISSN 2238-1031.

This paper is downloadable at www.transport-literature.org/open-access. 


\section{Introdução}

A desigualdade pode se expressar por meio de diferentes formas. As mais abrangentes se referem aos níveis de consumo pessoal, de utilização dos serviços públicos, de posse de bens e recursos, de segurança, de dignidade pessoal e de autonomia. No âmbito da estrutura urbana, geralmente, é fruto da má distribuição da renda e da falta de política habitacional adequada. Uma de suas consequências é a exclusão social que, segundo Castells (2009), resulta do afastamento progressivo do indivíduo da sociedade por meio de rupturas consecutivas com a mesma. No caso de população pobre, que tipicamente depende do transporte público para ter acesso aos equipamentos urbanos que se distribuem ao longo do território, esta ainda pode sofrer da imobilidade, isto é: ter dificuldade de acesso aos serviços essenciais e de conseguir emprego (Motte-Baumvol e Nassi, 2012). Principalmente quando o valor da passagem não é compatível com o orçamento familiar ou quando existem restrições de acesso às modalidades de transporte de maior capacidade e em particular as suas estações.

Em relação ao mundo em desenvolvimento, segundo Portugal et al. (2010), ocorreu, na América Latina, um processo de urbanização concentrado em algumas poucas cidades e uma ocupação pouco balanceada no território. É possível que as desigualdades de acesso aos meios de transportes e de oportunidades no espaço, que ocorrem nas escalas nacional e regional, e, com mais visibilidade, dentro das metrópoles, sejam resultados desse processo de urbanização.

De acordo com o CEPAL (2007), a América Latina e o Caribe conformam a região menos equitativa do mundo. Em 2008, os $20 \%$ mais ricos concentravam $75 \%$ da renda global (Milovic, 2011). Nesse contexto, a escassez acentua a exclusão de milhões de pobres, produzindo áreas metropolitanas que se caracterizam por apresentar redes de serviços e equipamentos insuficientes e de baixa qualidade; altos índices de violência urbana; elevada segregação espacial e déficit de moradias, que muitas vezes invadem áreas periféricas sem infraestrutura ou locais mais centrais de acesso restrito (favelas), formando bairros desconectados do sistema de transportes e sem planejamento urbano (Portugal et al., 2010). 
No Brasil, segundo o Ministério das Cidades (2013), em 2008, o déficit habitacional estimado correspondia a aproximadamente 5,5 milhões de domicílios, dos quais $83,5 \%$ estão localizados nas áreas urbanas. Apesar da queda do déficit habitacional verificada no Brasil a partir deste ano (2008), o montante ainda é expressivo.

Em um contexto em que se destacam a concentração de pessoas, a insuficiência de moradias e um planejamento inadequado, o que se pode supor é que a falta de recursos financeiros limite o deslocamento por todo o espaço urbano, com reflexos prejudiciais à população de baixa renda. Quando o sistema de transporte público é deficiente, os custos operacionais e as externalidades negativas aumentam, piorando ainda mais a situação, sendo esse um fenômeno típico de cidades em países pobres e que tem despertado a atenção das organizações mundiais. Segundo Maricato (2003), a ausência de uma política habitacional direcionada às moradias populares tem levado as pessoas a ocuparem os morros, o entorno dos corredores de transporte e a periferia. Como não existe uma infraestrutura para atender as suas necessidades básicas, estas vivem isoladas e em habitações precárias. De acordo com o Censo de 2010 do IBGE (2010), 6\% da população brasileira (11,4 milhões de pessoas) moram em aglomerados subnormais (favelas). Nas áreas urbanas, são cerca de 4,17 milhões de pessoas (Davis, 2006).

No que diz respeito aos postos de trabalho, ao contrário das fábricas que geralmente estão situadas em locais onde o valor do solo urbano é baixo, o setor de serviços (importante na geração empregos), para atender as classes de maior renda, se localizam em áreas valorizadas. Nessas circunstâncias, a distância entre o local de trabalho e a residência assume grande importância para os trabalhadores menos qualificados (CEPAL, 2007).

Segundo o IPEA (2011), na última década, tem-se observado uma tendência de maior crescimento da população residente na periferia das regiões metropolitanas brasileiras em comparação com a população dos municípios sedes dessas metrópoles. Isso pode ser confirmado pelo Censo do IBGE (2010), que aponta que a população das principais regiões metropolitanas cresceu de $25 \%$ a $90 \%$ a mais que os respectivos municípios sede, com exceção do Rio de Janeiro.

Esse padrão de crescimento das metrópoles leva a indagar sobre os seus efeitos sobre o padrão de mobilidade da população residente. Se os empregos continuarem fortemente concentrados nos municípios centrais, em particular nos seus núcleos centrais, há de se esperar um aumento 
das viagens intermunicipais pendulares, com efeitos fortes sobre o desempenho do sistema metropolitano de transporte: que é predominantemente rodoviário e opera em corredores congestionados (Portugal et al., 2010). Essa previsão indica que ficará ainda mais difícil o acesso ao transporte público pela população de menor poder aquisitivo e que mora na periferia.

Os estudos que abordam o problema das desigualdades apontam algumas diretrizes. O Banco Mundial (2013) propõe atingir objetivos tais como: melhor compreensão das deficiências de transporte urbano nos países em processo de desenvolvimento e identificação de qual a melhor forma de ajuda, concentrando-se nos problemas das pessoas mais pobres e nos seus locais de moradias e trabalho, com destaque para as questões da renda e da acessibilidade.

Litman (2013) propôs que a questão da equidade no setor de transporte fosse tratada em três dimensões: 1) A dimensão horizontal diz respeito à distribuição dos impactos entre indivíduos e grupos considerados iguais em capacidade e necessidade, com os subsídios só se justificando em caso de pobreza. 2) A dimensão vertical com relação à renda e classe social (justiça social, preservação ambiental e inclusão social) tem como preocupação a distribuição dos impactos entre os indivíduos e os grupos que diferem em suas habilidades e necessidades. Como consequência, as políticas de transporte devem favorecer aqueles que são econômica e socialmente desfavorecidos, compensando desigualdades. 3) A dimensão vertical com relação à dificuldade de locomoção visa a incentivar o uso do desenho universal, o que significa que as instalações e os serviços de transporte devem acomodar todos os usuários, incluindo aqueles com necessidades especiais.

A Secretaria Nacional de Transporte e Mobilidade Urbana (2007) pretende contribuir para que as mudanças no planejamento e na gestão das políticas de mobilidade urbana ocorram no maior número de cidades possível. Busca alterar significativamente o padrão de urbanização e de circulação nos municípios, além de colocar em prática um processo de desenvolvimento econômico sustentável que possa garantir inclusão social de toda a população.

A experiência dos países desenvolvidos de utilização do sistema sobre trilhos, com empregos e residências concentradas no entorno das estações, pode servir como um modelo para atenuar o problema da exclusão, aumentando as oportunidades para os moradores. As estações, os condomínios residenciais, os hospitais, as escolas, dentre outros Polos Geradores de Viagens 
(PGVs), atuando de forma integrada, podem criar um ambiente urbano com menos viagens motorizadas, reduzindo as despesas com transporte no orçamento familiar. Segundo Suzuki et al. (2013), empiricamente se podem confirmar em grande parte as teorias sobre os impactos positivos sobre a população por meio de investimentos nos modos ferroviários, como nos EUA (BART em San Francisco) e no Canadá (Toronto), sendo Copenhagen (na Dinamarca) e Estocolmo (na Suécia) os melhores exemplos de planejamento integrado entre trem e desenvolvimento socioeconômico.

De acordo com Sánches e Moura (2005), Cingapura se destaca como exemplo para países em desenvolvimento no que se refere à administração urbana e à integração entre transporte e ambiente urbano. Com base no sistema sobre trilhos, foi impulsionado o desenvolvimento socioeconômico e reduzida a pobreza, aumentando a oferta de empregos e a construção de moradias populares no entorno das estações, muitas vezes por meio dos PGVs.

No que diz respeito ao Brasil, suas áreas metropolitanas tiveram sua expansão orientada originalmente por um eficiente sistema trem suburbano-bonde, substituído posteriormente pelos ônibus. A eliminação do bonde e a degradação do serviço ferroviário, conjugada à expansão do uso do automóvel, provocaram a estagnação (e mesmo decadência) do transporte público de maior capacidade, transferindo essa tarefa para os ônibus e automóveis (Abreu, 2011). Como os serviços prestados pelos ônibus não se constituíram em alternativa para o transporte individual, as vias urbanas foram sendo congestionadas. A maioria das metrópoles brasileiras não dispõe de um planejamento integrado de transportes. Além disso, a ocupação histórica dos subúrbios e da periferia se fez com populações de baixo nível de renda.

A fim de reverter esse quadro, de acordo com o Ministério das Cidades, desde 2003 já foram disponibilizados $\mathrm{R}$ \$21,6 bilhões para infraestrutura de transporte urbano, que envolveram investimentos em transporte sobre trilhos em capitais como Rio de Janeiro, Porto Alegre, Salvador e Belo Horizonte. A previsão é que com a conclusão das obras o sistema de transporte urbano se constitua numa rede integrada que favoreça a população, diminua o trânsito e beneficie o meio ambiente (Portal Brasil, 2013).

Além disso, o Programa Estadual de Transportes - PET tem como objetivo a melhoria da qualidade e a integração dos serviços de transportes urbanos na Região Metropolitana do Rio de Janeiro, bem como o aumento da capacidade de oferta de lugares para atender a níveis de 
demanda da ordem de um milhão e duzentos mil passageiros/dia útil, beneficiando uma população estimada em 10,2 milhões de habitantes e 19 municípios (SECTRAN, 2011).

Esses investimentos devem gerar novos padrões de acessibilidade, possibilitando a integração das comunidades pobres que vivem ao longo dos ramais ferroviários, promovendo a inclusão social e garantindo uma demanda de passageiros compatível com a escala de transporte dos trens. Para isso, é fundamental entender a relação entre a presença da favela, sua proximidade e o porte com a demanda de passageiros pelo trem, expressa pelas taxas de embarque e desembarque das estações.

Em síntese, um projeto visando à criação de um ambiente com menos desigualdades deve priorizar a identificação de fatores que atuam nos múltiplos setores do ambiente urbano. Nesse sentido, propõe-se identificar as relações entre dois Polos Geradores de Viagens - as estações de trem e as favelas - visando à inclusão social. Inicialmente será elaborado um panorama da relação entre o transporte público e a exclusão social, destacando a implicação da disponibilidade do serviço de transporte com menor peso no orçamento familiar e que seja mais rápido. A seguir, serão conceituadas as favelas e as estações ferroviárias como PGVs, bem como identificados os fatores intervenientes na taxa de embarque nas estações. Por fim, pretende-se estruturar conceitualmente e de forma exploratória a influência da presença de favelas nas taxas de embarque e desembarque das estações, considerando que elas podem expressar a mobilidade (imobilidade) dessa comunidade, o que indica a necessidade ou não de intervenções direcionadas à inclusão social.

\section{Transporte público e exclusão social}

No momento da segunda revolução industrial, a generalização da energia elétrica e a utilização dos bondes, como já citado, permitiram a ampliação das concentrações urbanas de mão de obra em volta de unidades de produção industrial cada vez maior. Os transportes coletivos buscavam assegurar a integração das diferentes zonas e atividades da metrópole, distribuindo os fluxos internos segundo uma relação tempo/espaço suportável. O automóvel contribuiu para a dispersão urbana, com enormes zonas de residências unifamiliares, espalhadas por toda a região, e ligadas pelas vias expressas e de alta capacidade aos diferentes setores funcionais (Castells, 2009). Ainda de acordo com o mesmo autor, essa configuração 
urbana, tipicamente observada em cidades americanas, aumentou os custos do uso dos meios de transporte em tempo e em valor monetário. Como consequência, quando são identificadas desigualdades, as despesas associadas ao uso do transporte público deveriam ser compatíveis com os rendimentos da população de baixa renda. Fato que, geralmente, não se verifica em particular nos países menos desenvolvidos.

Cervero (2011) apresenta dados obtidos em cidades localizadas em várias partes do mundo que apontam a gravidade do problema do custo do uso do transporte público para quem recebe baixos salários. Nos assentamentos informais nos arredores da Cidade do México, os moradores chegam a fazer de dois a três transbordos para chegar a uma estação. Além disso, gastam mais de três horas no trajeto casa-trabalho. Para os moradores das partes altas da Cidade de Bogotá (Colômbia), a situação não é diferente. Além disso, estudos elaborados em Nairobi (Quênia), Delhi (India), Buenos Aires (Argentina), Manila (Filipinas) e Cidade do México (México) estimam que o trajeto casa-trabalho chega a consumir de $14 \%$ a $30 \%$ do salário diário.

Segundo o mesmo autor, o encargo financeiro desproporcional suportado pelas pessoas de menor poder aquisitivo para alcançar as oportunidades de trabalho não está limitado aos países em desenvolvimento. Mesmo nos EUA, os trabalhadores pobres gastam o dobro da porcentagem do salário em transporte em relação aos considerados não pobres, algo em torno de $6,1 \%$ contra 3,8\%. Adicionando os custos dos deslocamentos para as escolas, as lojas e os serviços de saúde, se chega a aproximadamente $20 \%$ dos salários.

Segundo estudo do IPEA (2012), baseado em dados de 2009, observa-se que as famílias que moram nas periferias metropolitanas apresentam os valores mais altos com o item deslocamento (16,43\%), muito em função do menor poder aquisitivo da população. Estudo de Motte-Baumvol e Nassi (2012) mostra que o índice de imobilidade dos moradores da Região Sul da Cidade do Rio de Janeiro, parte mais rica, é $18 \%$ menor do que o da Zona Norte. O mesmo é detectado na região metropolitana (diferença entre centro e periferia).

De acordo com Pereira e Schwanem (2013), o tempo dispendido nos deslocamentos casatrabalho nas maiores regiões metropolitanas brasileiras é inferior aos encontrados no estudo de Cervero (2011). Os autores, a partir de dados do Censo do IBGE (2010), verificaram que o intervalo do tempo médio de tais deslocamentos varia de 31,5 até 42,8 minutos. Sendo que os 
maiores tempos foram identificados em São Paulo $(42,8)$ e no Rio de Janeiro $(42,6)$. Considerando que nesses cálculos estão incluídos aqueles efetuados usando o automóvel particular, o tempo médio no transporte público deve convergir para os obtidos pelo autor supracitado.

Estudo do Banco Mundial (2013) aponta que o transporte urbano pode contribuir na redução da pobreza tanto indiretamente, por meio de seu impacto sobre a economia da cidade e, consequentemente, no seu desenvolvimento, como diretamente, por meio do atendimento das necessidades diárias de pessoas pobres. Além disso, há um consenso de que deve existir igualdade de oportunidades, mas o mesmo não acontece no que se refere à igualdade e distribuição justa dos resultados (Litman, 2013). O encaminhamento da equidade entre oportunidades e resultados pode ser feito por meio de uma política urbana com suporte no sistema sobre trilhos. Segundo Litmam (2004 apud Litman, 2013), o peso no orçamento familiar do item transporte para quem reside em locais atendidos por serviço de alta capacidade é menor em relação aos moradores de comunidades orientadas ao automóvel.

Suzuki et al. (2013) identificaram a importância da integração entre transporte e uso do solo com destaque ao sistema ferroviário para dar suporte a medidas que visem a reduzir o isolamento espacial e a exclusão social. A qualificação dessas medidas pode ser feita com base no conhecimento das peculiaridades locais. É a partir da estação que se tem acesso ao sistema ferroviário, logo o estudo das suas funções como elemento desse sistema e como equipamento do ambiente urbano pode esclarecer aspectos importantes e também indicar como ela deve atuar na melhoria do serviço e da qualidade de vida em seu entorno.

Bertolini e Spit (2007) identificaram a estação ferroviária como um "nó" (local de acesso ao trem e para outros meios de transporte em uma rede integrada) e "lugar" (setor da cidade com concentração de atividades). Segundo os autores, a complexidade das formas de interações entre esses dois domínios mostra que é fundamental a identificação de aspectos relativos a ambos. A consistência de uma proposta de revitalização de um sistema ferroviário deverá ter como suporte a harmonia entre os elementos que caracterizam a estação como "nó' e como "lugar" do ambiente urbano. Pode-se caminhar nessa direção balanceando a capacidade de transporte ofertada pela estação ("nó”) com a demanda de viagens geradas pelas atividades no seu entorno ("lugar"), o que reflete o nível de aproveitamento que a localidade dá ao recurso coletivo disponibilizado pelo transporte. Nesse sentido, quando há folga de capacidade de 
transporte na estação, é possível considerar o incentivo de atividades, como os PGVs, para gerar mais viagens. Caso contrário, deve-se ampliar a oferta no serviço ferroviário. Kuby et al. (2004), Reusser et al. (2008), Sohn e Shin (2010) e Zemp et al. (2010) investigaram os fatores que influenciam a demanda por trem expressa pela taxa de embarque e desembarque nas estações e pela presença de PGVs no entorno das estações (ver itens 3 e 4). Embora os aspectos do ambiente socioeconômico tenham sido apontados como relevantes na busca pelo equilíbrio da estação como "nó" e "lugar", não são conhecidas pesquisas que tenham investigado a atuação das favelas.

\section{As favelas e as estações ferroviárias como polos geradores de viagens}

De acordo com o Censo Demográfico efetuado pelo IBGE (2010), existem no Brasil 6.329 favelas, onde estão alocadas 3.224.529 domicílios. Considerando-se que o Instituto Brasileiro de Geografia e Estatística (2010) define a favela brasileira como um aglomerado subnormal com mais de 509 unidades domiciliares (domicílios/favelas), ela pode ser caracterizada como um Polo Gerador de Viagens, levando em conta que vários estudos e legislações municipais determinam que isso ocorre para empreendimentos residenciais com mais de 200 unidades habitacionais (Grieco et al., 2012).

Outro aspecto que deve ser considerado é a localização. Segundo Davis (2006), as favelas podem ser classificadas em: pertencentes ao núcleo metropolitano ou a periferia. Segundo o autor, aquelas que estão situadas no núcleo metropolitano das cidades dos países pobres variam na faixa de $17 \%$ até $34 \%$ do total existente, enquanto as localizadas na periferia variam de $66 \%$ até $83 \%$. Na Cidade do Rio de Janeiro, 23\% estão situadas no núcleo metropolitano e $77 \%$ na periferia. Nesse contexto, quando o transporte público é deficiente, a imobilidade tende a ser maior para os moradores das favelas da periferia, o que também reforça o papel dos trens como opção de transportes pela sua propensão a melhor atender às viagens de média a longa distância (Cardoso, 2012).

Conforme Grieco et al. (2012), o uso residencial apresenta grande diversidade de tipologias construtivas, criadas em função de condições geográficas, políticas, ambientais e sociais. $\mathrm{O}$ ITE (2010) correlaciona essa classificação de tipologias com as taxas e modelos de geração de viagens. Os parâmetros usados na sua definição como PGV variam de acordo com países e 
cidades. No Brasil, só recentemente tem havido uma preocupação em modelar a demanda de viagens em atividades residenciais (Grieco et al., 2012). No caso das favelas, não se encontraram na bibliografia consultada pesquisas sobre geração de viagens e muito menos estudos quanto a sua relação com as taxas de embarque e desembarque. Entretanto, há indícios que a sua presença tende a influenciar tais taxas. De acordo com Pereira (2011), no que diz respeito às funções desenvolvidas pelos empreendimentos ou lugares, dentre as atividades com maior potencial de atração de viagens estão as favelas.

Quanto à estação ferroviária, na época da implantação desse sistema de transporte, a maioria das viagens atraídas era do tipo a pé, pois a ocupação das moradias era menos espalhada e concentrada próxima das estações e os deslocamentos efetuados eram em sua maioria para levar e trazer os trabalhadores de suas casas para o trabalho. Atualmente, com a implantação de linhas alimentadoras de transportes e a alocação de equipamentos urbanos no entorno das estações, o seu funcionamento depende da chegada de usuários que utilizam ônibus, automóveis e bicicletas. As opções de chegada exercem influência na taxa de embarque e atraem atividades para o seu interior (Gonçalves et al., 2012b).

O ITE (2010) fez estimativas da demanda por vagas em estacionamento do tipo "park-andride" nas estações de "Light Rail Train" existentes nos Estados Unidos. O objetivo do estudo era relacionar a taxa de embarque com o número de vagas de estacionamento nas estações, considerando possibilidades de atrair os usuários dos automóveis para o transporte público. No Brasil, levando em conta as favelas, a implantação de teleféricos, ligando os morros às estações, é um tipo de integração voltada para a população carente que pode ser estudada relacionando passageiros desse modo de transporte com a taxa de embarque. O Teleférico do Alemão indicou uma tendência de aumento na taxa de embarque na estação de integração (Gonçalves et al., 2012b). Em outras favelas do Rio de Janeiro, tecnologias diferentes foram implantadas para atenuar o problema da acessibilidade: no Morro Cantagalo, elevador, e nas comunidades do Pavão-Pavãozinho e Morro Santa Marta, plano inclinado.

A identificação das funções exercidas pela estação ferroviária oferece um panorama global de inserção do trem no sistema de transporte e no meio urbano (Bertolini e Spit, 2007). No entanto, quem está envolvido com a geração de viagens e com a demanda ferroviária necessita identificar aspectos locais que interferem diretamente na taxa de embarque. Segundo Portugal (2012), pesquisas de campo e modelos matemáticos são instrumentos utilizados com 
frequência nos estudos disponíveis na literatura de transporte e, dessa forma, podem dar suporte aos técnicos envolvidos com a questão da produção de viagens. Em relação às favelas, deve-se ressaltar que, além da exclusão promovida pelo transporte público e motorizado para os seus moradores, não só pelas distâncias a serem vencidas, como pelos custos associados e mesmo pelas superlotações, há carência de atividades essenciais e serviços na vizinhança alcançáveis a pé e por bicicletas. A identificação dos fatores intervenientes na taxa de embarque e desembarque pode propiciar uma melhor compreensão do papel exercido, atualmente, pelas favelas, no ambiente urbano.

\section{Fatores intervenientes nas taxas de embarque e desembarque nas estações de trem}

Com o surgimento do ônibus e do automóvel, morar próximo da estação do trem deixou de ser uma necessidade e essa modalidade perdeu a sua importância. Atualmente além da escassez de áreas urbanas para a construção de vias e de estacionamentos se tem a questão ambiental e o isolamento espacial da população carente.

Com as vias urbanas ocupadas em sua totalidade por automóveis e ônibus e o esgotamento de áreas urbanas para a expansão, o trem volta a ser um elemento importante no equacionamento do problema da mobilidade. Entretanto, os usuários têm características diferentes da época de sua implantação. O modo de transporte rodoviário incorporou novas exigências. Hoje não basta, por exemplo, a pontualidade para evitar atrasos no trabalho. Investigar o que as pessoas esperam do sistema ferroviário, onde implantar novos corredores, como adaptar a infraestrutura ferroviária existente à nova realidade e como projetar um ambiente urbano onde a mobilidade não implique mais poluição passou a fazer parte das preocupações de urbanistas e de pesquisadores de transporte. Na prática, isso significa detectar como as pessoas interagem, nos seus deslocamentos, com a infraestrutura ferroviária.

A partir de Gonçalves et al. (2012a), que tratam dos fatores intervenientes e que determinam a taxa de embarque e desembarque nas estações ferroviárias, sua revisão bibliográfica foi ampliada e atualizada, como mostra a Tabela 1. 
Tabela 1 - Fatores intervenientes nas taxas de embarque/desembarque presentes na área de influência das estações ferroviárias

\begin{tabular}{|c|c|c|c|c|c|c|c|c|c|c|c|c|c|c|c|c|}
\hline \multirow[b]{2}{*}{ Fator } & \multirow[b]{2}{*}{ Indicadores } & \multirow[b]{2}{*}{ Descrição } & \multirow[b]{2}{*}{$\begin{array}{l}\mathbf{S} \\
\mathbf{i} \\
\mathbf{n} \\
\mathbf{a} \\
\mathbf{l}\end{array}$} & \multicolumn{13}{|c|}{ Autores } \\
\hline & & & & $\begin{array}{l}\text { Quade } \\
\text { e Dou- } \\
\text { glas } \\
(\mathbf{1 9 9 6})\end{array}$ & $\begin{array}{c}\text { Wal- } \\
\text { ters e } \\
\text { Cerver } \\
o \\
(2003)\end{array}$ & $\begin{array}{l}\text { Chu } \\
(2004)\end{array}$ & $\begin{array}{l}\text { Kuby } \\
\text { et al. } \\
(2004)\end{array}$ & $\begin{array}{l}\text { Anspa } \\
\text {-cher } \\
(2005)\end{array}$ & $\begin{array}{l}\text { Brons } \\
\text { et al. } \\
(2008)\end{array}$ & $\begin{array}{l}\text { Debre- } \\
\text { zion } e t \\
\text { al. } \\
(2009)\end{array}$ & $\begin{array}{l}\text { Sohn e } \\
\text { Shim } \\
\text { (2010) }\end{array}$ & $\begin{array}{l}\text { Gutié- } \\
\text { rrez et } \\
\text { al. } \\
(2011)\end{array}$ & $\begin{array}{l}\text { Basu e } \\
\text { Hunt } \\
\text { (2012) }\end{array}$ & $\begin{array}{c}\text { Gon- } \\
\text { çalves } \\
\text { et al. } \\
(2012 \mathrm{a} \\
\quad)\end{array}$ & $\begin{array}{l}\text { Brown } \\
\text { et al. } \\
(2013)\end{array}$ & $\begin{array}{l}\text { Frei e } \\
\text { Mahm } \\
\text { assani } \\
(\mathbf{2 0 1 3})\end{array}$ \\
\hline & $\begin{array}{l}\text { TOD - Transport } \\
\text { Oriented }\end{array}$ & & & & & & & & & & & & & & & \\
\hline & $\begin{array}{l}\text { Oriented } \\
\text { Development }\end{array}$ & Projeto Urbanístico & + & & $X$ & & $X$ & & & & $\mathrm{x}$ & $\mathrm{x}$ & & $\mathrm{x}$ & $\mathrm{x}$ & $\mathrm{x}$ \\
\hline Uso & $\begin{array}{l}\text { Empregos na Área } \\
\text { de Influência }\end{array}$ & Número de empregos & + & $\mathrm{x}$ & & $\mathrm{x}$ & $\mathrm{X}$ & & & & $\mathrm{x}$ & $\mathrm{x}$ & & $\mathrm{x}$ & $\mathrm{x}$ & \\
\hline do & População & Número de habitantes & + & $\mathrm{x}$ & $X$ & & $\mathrm{X}$ & $\mathrm{X}$ & $\mathrm{x}$ & & $\mathrm{x}$ & $\mathrm{x}$ & & $\mathrm{x}$ & $\mathrm{x}$ & \\
\hline \multirow[t]{2}{*}{ solo } & $\begin{array}{l}\text { Polos Geradores de } \\
\text { Viagens }\end{array}$ & $\begin{array}{l}\text { Instituições de Ensino; Aeroportos; } \\
\text { Rodoviárias; Centros Comerciais, } \\
\text { Financeiros, Hospitalares, } \\
\text { Desportivos e de Lazer. }\end{array}$ & + & & & & $\mathrm{X}$ & & & & $\mathrm{x}$ & $\mathrm{x}$ & & $\mathrm{x}$ & & $\mathrm{x}$ \\
\hline & Centro da Cidade & Atração de Pessoas e Negócios & + & $\mathrm{x}$ & & & $\mathrm{X}$ & & $\mathrm{x}$ & & $\mathrm{x}$ & & & $\mathrm{x}$ & $\mathrm{x}$ & \\
\hline \multirow[b]{2}{*}{$\begin{array}{l}\text { Ambi- } \\
\text { ente }\end{array}$} & Segurança Pública & Repulsão/Atração de Passageiros & + & & & & & & $\mathrm{x}$ & & & & & $\mathrm{x}$ & & $\mathrm{x}$ \\
\hline & $\begin{array}{l}\text { Proximidade com } \\
\text { fronteiras } \\
\text { internacionais }\end{array}$ & Fluxo de Pessoas & + & & & & $\mathrm{X}$ & & & & & & & & & \\
\hline \multirow{3}{*}{$\begin{array}{l}\text { Urba- } \\
\text { no }\end{array}$} & Climas extremos & Podem Desestimular Viagens. & - & & & & $\mathrm{X}$ & & $\mathrm{x}$ & & & & & & & \\
\hline & Área turística & Atração de passageiros & + & & & & & & & & & & & $\mathrm{x}$ & & \\
\hline & Acidentes & $\begin{array}{l}\text { Mortes por Deficiência no acesso a } \\
\text { Pé. }\end{array}$ & - & & & & & & & & & & & $\mathrm{x}$ & & \\
\hline \multirow{9}{*}{$\begin{array}{l}\text { Aspec- } \\
\text { tos } \\
\text { Socio- } \\
\text { econô- } \\
\text { micos }\end{array}$} & Renda & Renda Familiar Média & $*$ & & $\mathrm{X}$ & $\mathrm{x}$ & $\mathrm{X}$ & $\mathrm{X}$ & $\mathrm{x}$ & & & & & $\mathrm{x}$ & $\mathrm{x}$ & $\mathrm{x}$ \\
\hline & IDH & $\begin{array}{l}\text { Ferrovia Tende a Promover } \\
\text { Desenvolvimento Socioeconômico. }\end{array}$ & + & & & & & & & & & & & $\mathrm{x}$ & & \\
\hline & $\begin{array}{l}\text { Taxa de } \\
\text { Desemprego }\end{array}$ & Imobilidade & - & & & & & & & & & & & & $\mathrm{x}$ & $\mathrm{x}$ \\
\hline & Escolaridade & Instrução da População Residente & + & & & & & & $\mathrm{x}$ & & & & & & & \\
\hline & $\begin{array}{l}\text { Porcentagem de } \\
\text { inquilino na área } \\
\text { de influência }\end{array}$ & $\begin{array}{l}\text { Tendem a Ser de Baixa Renda, } \\
\text { Jovens e Dividir Habitações onde } \\
\text { pode não haver estacionamento. }\end{array}$ & + & & & & $\mathrm{X}$ & & & & & & & & & \\
\hline & Faixa etária & Capacidade de Deslocamento. & $*$ & & & $\mathrm{x}$ & & $\mathrm{X}$ & $\mathrm{x}$ & & & $\mathrm{x}$ & & & & $\mathrm{x}$ \\
\hline & Gênero & $\begin{array}{l}\text { Os Homens Tendem a Ter Maior } \\
\text { Mobilidade. }\end{array}$ & $*$ & & & $\mathrm{x}$ & & $\mathrm{X}$ & & & & & & & & \\
\hline & Etnia & Diferentes Padrões de Viagens. & $*$ & & $\mathrm{X}$ & & & $\mathrm{X}$ & $\mathrm{x}$ & & & $\mathrm{x}$ & & & $\mathrm{x}$ & \\
\hline & Veículos & $\begin{array}{l}\text { Número de Veículos Particulares } \\
\text { Por Residência. }\end{array}$ & $*$ & & & $\mathrm{x}$ & & & $\mathrm{x}$ & & & $\mathrm{x}$ & & & $\mathrm{x}$ & $\mathrm{x}$ \\
\hline
\end{tabular}




\begin{tabular}{|c|c|c|c|c|c|c|c|c|c|c|c|c|c|c|c|c|}
\hline \multirow[b]{2}{*}{ Fator } & \multirow[b]{2}{*}{ Indicadores } & \multirow[b]{2}{*}{ Descrição } & \multirow[b]{2}{*}{$\begin{array}{l}\mathbf{S} \\
\mathbf{i} \\
\mathbf{n} \\
\mathbf{a} \\
\mathbf{l}\end{array}$} & \multicolumn{13}{|c|}{ Autores } \\
\hline & & & & $\begin{array}{l}\text { Quade } \\
\text { e Dou- } \\
\text { glas } \\
(\mathbf{1 9 9 6})\end{array}$ & $\begin{array}{c}\text { Wal- } \\
\text { ters e } \\
\text { Cerver } \\
\text { o } \\
(2003)\end{array}$ & $\begin{array}{l}\text { Chu } \\
(2004)\end{array}$ & $\begin{array}{l}\text { Kuby } \\
\text { et al. } \\
(2004)\end{array}$ & $\begin{array}{l}\text { Anspa } \\
\text {-cher } \\
(\mathbf{2 0 0 5})\end{array}$ & $\begin{array}{l}\text { Brons } \\
\text { et al. } \\
(\mathbf{2 0 0 8})\end{array}$ & $\begin{array}{l}\text { Debre- } \\
\text { zion } \text { et } \\
\text { al. } \\
(2009)\end{array}$ & $\begin{array}{l}\text { Sohn e } \\
\text { Shim } \\
(\mathbf{2 0 1 0})\end{array}$ & $\begin{array}{l}\text { Gutié- } \\
\text { rrez et } \\
\text { al. } \\
(2011)\end{array}$ & $\begin{array}{l}\text { Basu e } \\
\text { Hunt } \\
(\mathbf{2 0 1 2})\end{array}$ & $\begin{array}{l}\text { Gon- } \\
\text { çalves } \\
\text { et al. } \\
(2012 \mathrm{a} \\
\quad)\end{array}$ & $\begin{array}{l}\text { Brown } \\
\text { et al. } \\
(\mathbf{2 0 1 3})\end{array}$ & $\begin{array}{l}\text { Frei e } \\
\text { Mahm } \\
\text { assani } \\
(\mathbf{2 0 1 3})\end{array}$ \\
\hline \multirow{7}{*}{$\begin{array}{l}\text { Siste- } \\
\text { ma } \\
\text { de } \\
\text { Trans- } \\
\text { porte }\end{array}$} & $\begin{array}{l}\text { Integrações } \\
\text { Intermodais , } \\
\text { Acessibilidade }\end{array}$ & $\begin{array}{l}\text { Ônibus Alimentadores; e Vagas de } \\
\text { Estacionamento, Bicicletário, } \\
\text { Ciclovias e Ruas sem Saída no } \\
\text { Entorno. }\end{array}$ & + & $\mathrm{x}$ & $\mathrm{X}$ & & $\mathrm{X}$ & $\mathrm{X}$ & $\mathrm{x}$ & $\mathrm{x}$ & $\mathrm{x}$ & $\mathrm{x}$ & & $\mathrm{x}$ & & \\
\hline & $\begin{array}{l}\text { Congestionamento } \\
\text { de Rodovias }\end{array}$ & $\begin{array}{l}\text { Incentivo ao Transporte } \\
\text { Metroferroviário. }\end{array}$ & + & & & & & & & & & & & $\mathrm{x}$ & & \\
\hline & $\begin{array}{l}\text { Qualidade de } \\
\text { Serviço e Imagem }\end{array}$ & $\begin{array}{l}\text { Tarifa; Pontualidade; Tempo de } \\
\text { Espera e de Viagem; Facilidade de } \\
\text { Compra do Bilhete; Nível de } \\
\text { Aglomeração; Informação; } \\
\text { Climatização; Atendimento } \\
\text { (Simpatia) e Limpeza }\end{array}$ & + & & & & & $\mathrm{X}$ & $\mathrm{x}$ & $\mathrm{x}$ & & & $\mathrm{x}$ & $\mathrm{x}$ & $\mathrm{x}$ & $\mathrm{x}$ \\
\hline & Acessibilidade a pé & $\begin{array}{l}\text { Distância e Qualidade de } \\
\text { Caminhada; Passagens de Pedestre } \\
\text { Bloqueadas; Nós de Pedestres. }\end{array}$ & $*$ & $\mathrm{x}$ & & $\mathrm{x}$ & $\mathrm{X}$ & & & $\mathrm{x}$ & $\mathrm{x}$ & & & $\mathrm{x}$ & & $\mathrm{x}$ \\
\hline & Concorrência & Linhas de Ônibus Concorrentes. & - & & & & & & & & $\mathrm{x}$ & & & & & \\
\hline & Valor da Gasolina & $\begin{array}{l}\text { Incentiva o Uso de Transporte } \\
\text { Público }\end{array}$ & + & & & & & & & & & & & & & $\mathrm{x}$ \\
\hline & $\begin{array}{l}\text { Nível de } \\
\text { Congestionamento }\end{array}$ & Fluidez & - & & & & $X$ & & & & & & $\mathrm{x}$ & & & \\
\hline \multirow{6}{*}{$\begin{array}{l}\text { Estru- } \\
\text { tura } \\
\text { da } \\
\text { rede }\end{array}$} & Estação Terminal & Abrangência da Área de Influência. & + & $\mathrm{x}$ & & & $\mathrm{X}$ & & & & & & & & & \\
\hline & $\begin{array}{l}\text { Distância entre } \\
\text { Estações }\end{array}$ & Abrangência da Área de Influência. & & $\mathrm{x}$ & & & $\mathrm{X}$ & & & & & & & $\mathrm{x}$ & & \\
\hline & Centralidade & Atratividade & + & & & & $\mathrm{X}$ & & & $\mathrm{x}$ & $\mathrm{x}$ & & & $\mathrm{x}$ & & \\
\hline & Conectividade & $\begin{array}{l}\text { Estação, de Transferências } \\
\text { Necessárias para a viagem e de } \\
\text { Acessos. }\end{array}$ & $*$ & $\mathrm{x}$ & $\mathrm{X}$ & $\mathrm{x}$ & $\mathrm{X}$ & & $\mathrm{x}$ & & $\mathrm{x}$ & $\mathrm{x}$ & $\mathrm{x}$ & & & \\
\hline & $\begin{array}{l}\text { Intervalo Entre os } \\
\text { Trens }\end{array}$ & Tempo de Espera & - & & $X$ & & $\mathrm{X}$ & & $\mathrm{x}$ & $\mathrm{x}$ & & & & & & \\
\hline & Tecnologia & Tipo de Veículo & $*$ & & $\mathrm{X}$ & & & & & & & & & & & \\
\hline
\end{tabular}


A elaboração da Tabela 1 tem como premissa que a quantidade de viagens realizadas em uma estação ferroviária é influenciada por diferentes fatores, como os associados ao uso do solo, ao ambiente urbano, aos aspectos socioeconômicos, ao sistema de transporte e à estrutura da rede. Como consequência, se busca identificar as peculiaridades de cada um deles, os principais indicadores que representam os fatores e sua relação com 14 estudos levantados na bibliografa. Deve-se ressaltar que os 3 primeiros fatores são mais abrangentes e os dois últimos, direcionados ao setor de transportes e convergindo para a estrutura ferroviária.

\section{Análise dos fatores intervenientes}

O sistema metroferroviário se caracteriza por transportar grandes contingentes de viagens o que exige uma oferta de lugares compatível, não só para proporcionar uma adequada qualidade de serviço, mas também para garantir sua viabilidade financeira e mesmo funcional.

Essa demanda de viagens depende da densidade de atividades adjacentes às estações e da quantidade de pessoas nelas envolvidas, que representam as que moram e as que trabalham no local e que derivam do tipo de uso do solo desenvolvido: residencial, comercial, industrial e serviços. Há, porém, outros elementos que interferem em tal demanda, até porque atualmente é diferente da época da implantação do trem, quando, de um modo geral, as estações eram acessadas tipicamente a pé e por bicicleta, considerando que os automóveis eram raros. $\mathrm{O}$ aumento da população, seu espalhamento pelo território, a diversificação dos empregos e o surgimento do automóvel alterou esse quadro e tornou o acesso ao sistema ferroviário mais complexo.

Como tal acesso é feito por meio da estação, os aspectos do seu entorno, tais como existência de um planejamento com base no TOD, importância e impactos dos PGVs e atividades socioeconômicas, precisam ser identificados, estudados e articulados. Além disso, atuar na eliminação das restrições associadas ao ambiente físico e ao social (inclusive o preconceito racial e de diferentes naturezas), ressaltando a importância da estação no âmbito da estruturação do território e de suas centralidades, não só no contexto local, mas se estendendo para dimensões mais abrangentes.

Se quantitativamente, em termos de pessoas, equipamentos e atividades, a lógica local e da vizinhança, que integra transporte e uso do solo, pode ser adequada para refletir a demanda de viagens, qualitativamente pode não acontecer o mesmo, sugerindo uma lógica mais global e 
que considera todo o ambiente urbano. Identificar as expectativas das pessoas que vivem no entorno e a função da estação no processo de funcionamento da cidade é relevante e não pode se descartado.

Essa abordagem se amplia e se refina acrescentando-se fatores como os socioeconômicos, o sistema de transporte e a estrutura da rede ferroviária. Quanto aos aspectos socioeconômicos, o objetivo deve ser disponibilizar um serviço de transportes digno, considerando as possiblidades e necessidades das pessoas em termos de renda, capacidade física e cultural.

O conhecimento do fator sistema de transporte define as intervenções que devem ser executadas em nível operacional. Os indicadores associados a ele permitem avaliar a qualidade, a imagem e a atratividade do serviço ferroviário perante as outras modalidades; dimensionar a abrangência da integração modal - identificando a extensão e a qualidade da integração com as demais modalidades e também a não motorizada; bem como apontar onde e como se deve agir para atrair usuários para o sistema ferroviário.

A identificação dos aspectos da estrutura de rede dá uma visão mais física e funcional da oferta ferroviária e do papel que cada estação desempenha.

Especificamente em relação aos indicadores associados a esses cinco fatores: uso do solo, ambiente urbano, socioeconômicos, sistema de transporte e estrutura da rede, Gonçalves et al. (2012b) consideram como fundamentais e que influenciam na taxa de embarque os seguintes: população, empregos, a distância das residências e dos empregos até a estação e a política tarifária e de integração com modais alimentadores. Além destes, a Tabela 1 ressalta, pela quantidade de citações, o TOD, a qualidade de serviço e imagem modal, a acessibilidade a pé e a conectividade da estação.

Uma grande densidade de residentes no entorno de uma estação e de empregos em outras pode proporcionar uma interação entre elas e uma demanda significativa ao sistema ferroviário, embora não seja suficiente. Deve haver articulação entre os fatores. Por exemplo, o conforto e a rapidez proporcionada pelo trem no transporte de muitas pessoas e a atratividade da estação são catalizadores que podem criar um ambiente onde o desenvolvimento seja orientado pelo transporte integrado, tanto no que se refere às modalidades quanto à política tarifária. 
Por outro lado, quando são identificados problemas, uma ação articulada pode contribuir no aumento da taxa de embarque e desembarque. Por exemplo, nos corredores congestionados, os estacionamentos dissuasórios oferecidos aos motoristas podem atrai-los para o trem, desestimulando o uso do automóvel.

Um indicador que contribui para o aumento da demanda ferroviária e diz respeito ao fator estrutura da rede é a tecnologia. A necessidade de ampliação do sistema sobre trilhos suscita a discussão da tecnologia mais apropriada para cada cidade (Metrô e LRT). Como há um custo relativamente mais alto para a implantação de uma linha de trem, é fundamental que haja atratividade em suas estações para viabilizar o empreendimento.

Todas essas questões podem ser analisadas quantitativa e qualitativamente com base nos fatores identificados e nos seus respectivos indicadores por meio do estudo da taxa de embarque e desembarque nas estações. Embora sejam necessários aprofundamentos envolvendo conhecimentos teóricos das áreas que abarcam os fatores assinalados, os resultados quantitativos podem dar um panorama do nível de integração entre transporte e tipo de uso do solo e prever cenários onde se pretende incluir socialmente pessoas que vivem em condições de isolamento espacial, como parece ser o caso de determinadas comunidades das favelas que costumam existir ao longo dos ramais ferroviários.

\section{As favelas, as taxas de embarque-desembarque e as potencialidades de inclusão}

Embora na revisão bibliográfica não tenham sido identificados estudos específicos sobre indicadores relacionados com a influência das favelas na taxa de embarque, observa-se na maioria dos trabalhos contemplados na Tabela 1 que há preocupação com a população e com a renda. Uma das características desse tipo de comunidade é agrupar um grande contingente populacional de baixa renda. Nesse caso, se a população tende a contribuir para aumentar a taxa de embarque, a baixa renda tende a reduzi-la. Entretanto, existem outros aspectos que tornam esses agrupamentos sociais diferentes dos bairros das cidades. Assim, levando em conta a existência de uma favela na área de influência da estação e tendo-se a preocupação com a sua inclusão social, devem ser consideradas as peculiaridades locais, caso contrário, aspectos importantes relacionados à estação como "lugar" estariam sendo descartados e prejudicando o equilíbrio entre os domínios considerados ("nó" e "lugar"). 
Em relação à favela, suas principais características dispõem de elementos associados aos indicadores tradicionais, além de um aspecto negativo relacionado à criminalidade, fruto normalmente da ausência do poder público, que pode levar a uma visão preconceituosa por parte de alguns e que deve ser combatida. No que se refere à ocupação da população que mora nas favelas, de um modo geral, é detectado um grande número de trabalhadores que estão empregados no setor de serviço e precisam do transporte público para se deslocar.

Outro aspecto que deve ser observado é a maneira como os equipamentos são alocados no seu interior, lembrando os bairros antigos, onde, no entorno de uma praça, residências e comércio eram agrupados. Assim, intuitivamente, se pode afirmar que a presença de uma comunidade desse tipo interfere na taxa de embarque e desembarque na estação, pois ela tem uma função similar aos bairros operários das cidades industriais. O que precisa ser investigado é a mobilidade dos seus moradores e o papel que o trem exerce para atender as suas necessidades de locomoção.

Com base na premissa de que a favela tem semelhanças com os bairros operários, é relevante buscar identificar se seu porte é compatível com a demanda de viagens existente na área e em particular com as taxas de embarque e desembarque, se sua proximidade e tipologia facilitam o acesso à estação e se a renda familiar de seus moradores permite a utilização do trem. Uma atuação nesse sentido é articular a favela e a estação ferroviária na perspectiva de PGVs, levando em conta que a baixa geração de viagens pode também representar um sinal de imobilidade por parte da comunidade que vive na vizinhança (Figura 1). Em tais condições se justificam medidas destinadas à inclusão dessas pessoas, melhorando o seu acesso às estações e atraindo novas atividades no entorno orientadas as suas necessidades, inclusive de emprego. 


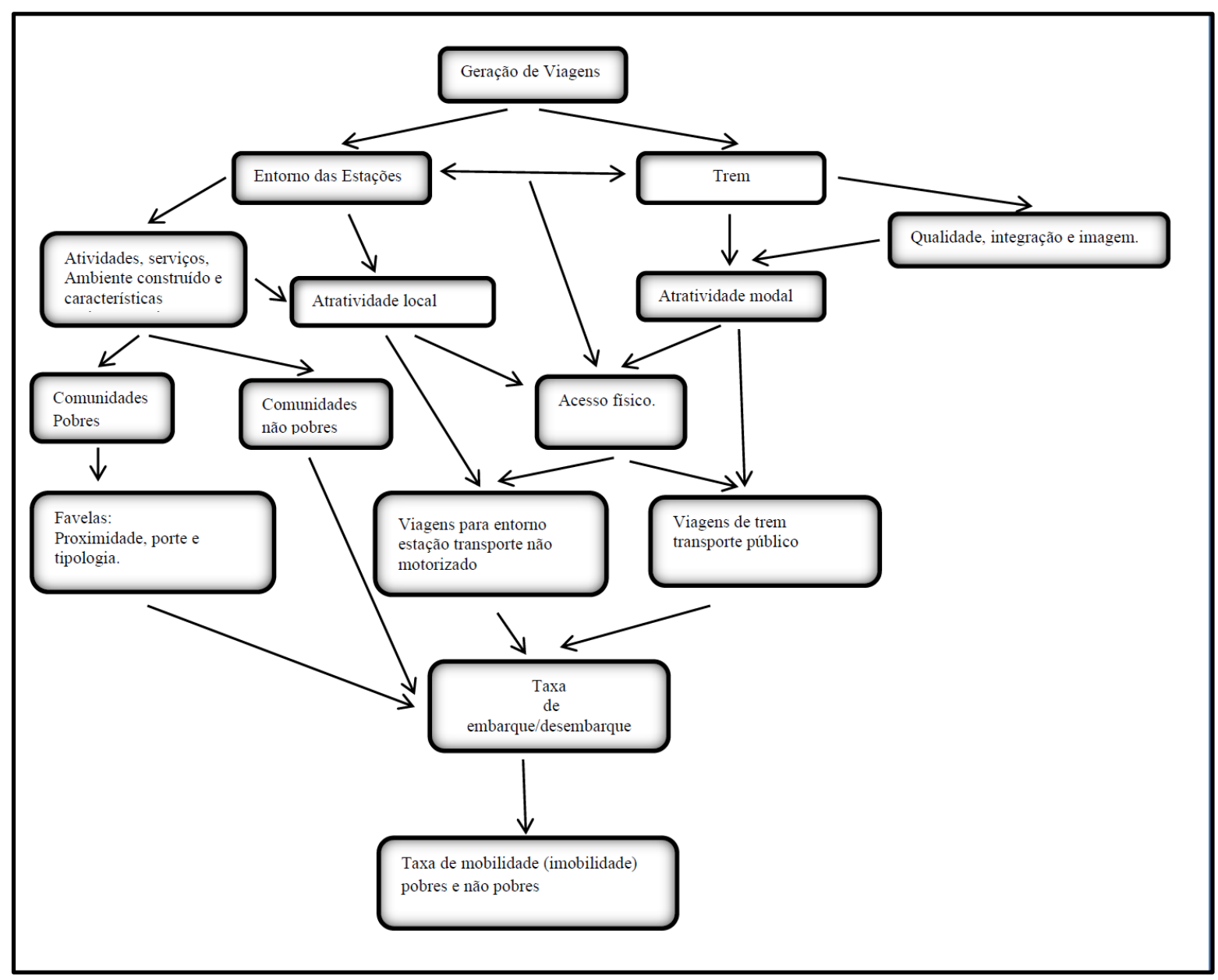

Figura 1. Esquema que contextualiza a relação entre a favela e a (i)mobilidade ferroviária

No sentido de caracterizar o nível de mobilidade (ou imobilidade) dessas comunidades e consequentes necessidades de intervenções direcionadas a melhoria da sua acessibilidade e integração, algumas etapas podem ser consideradas (ver Figura 2), segundo um modelo simplificado que se concentra na mobilidade por trem expressa pelas taxas de embarque e desembarque verificadas nas estações, tais como:

i. Caracterizar o corredor ferroviário de passageiros e todas as suas estações, bem como levantar e sistematizar as informações básicas no seu entorno e associadas aos principais fatores intervenientes na geração de viagens por trem, como população, emprego, renda, dentre outros mostrados na Tabela 1. 
ii. Classificar as estações não só quanto à presença da favela, mas também quanto à proximidade, ao tipo (por exemplo: topografia) e ao porte de cada uma delas, pressupondo-se que são variáveis que podem influenciar na geração de viagens por trem;

iii. Determinar a taxa de embarque e desembarque para cada estação do ramal que reflete a mobilidade da comunidade adjacente, inclusive da que mora na favela, se for o caso, no que diz respeito ao uso dessa modalidade ferroviária;

iv. Analisar comparativamente e qualitativamente os valores obtidos quanto às taxas de embarque e desembarque, considerando os fatores intervenientes bem como a presença ou não de uma favela no entorno. Também estabelecer as relações existentes entre tais fatores - em particular, a presença, a proximidade, o porte e a tipologia da favela - com tais taxas, no sentido de capturar as possíveis interferências da favela na geração de viagens por trem;

v. Aprofundar essa investigação, por meio de modelos econométricos, identificando os fatores e respectivos indicadores que melhor explicam a taxa de embarque, em particular o papel das favelas;

vi. Estabelecer se as favelas (e quais delas) tendem a contribuir ou não com a geração de viagens por trem. O resultado pode refletir o nível de mobilidade dessa comunidade e indicar a necessidade ou não de intervenções;

vii. Caracterizar a natureza e a intensidade dessa necessidade, selecionando os tipos de intervenções mais adequados e que incentivem a integração da comunidade à estação e às atividades vizinhas, promovendo um ambiente de inclusão. 


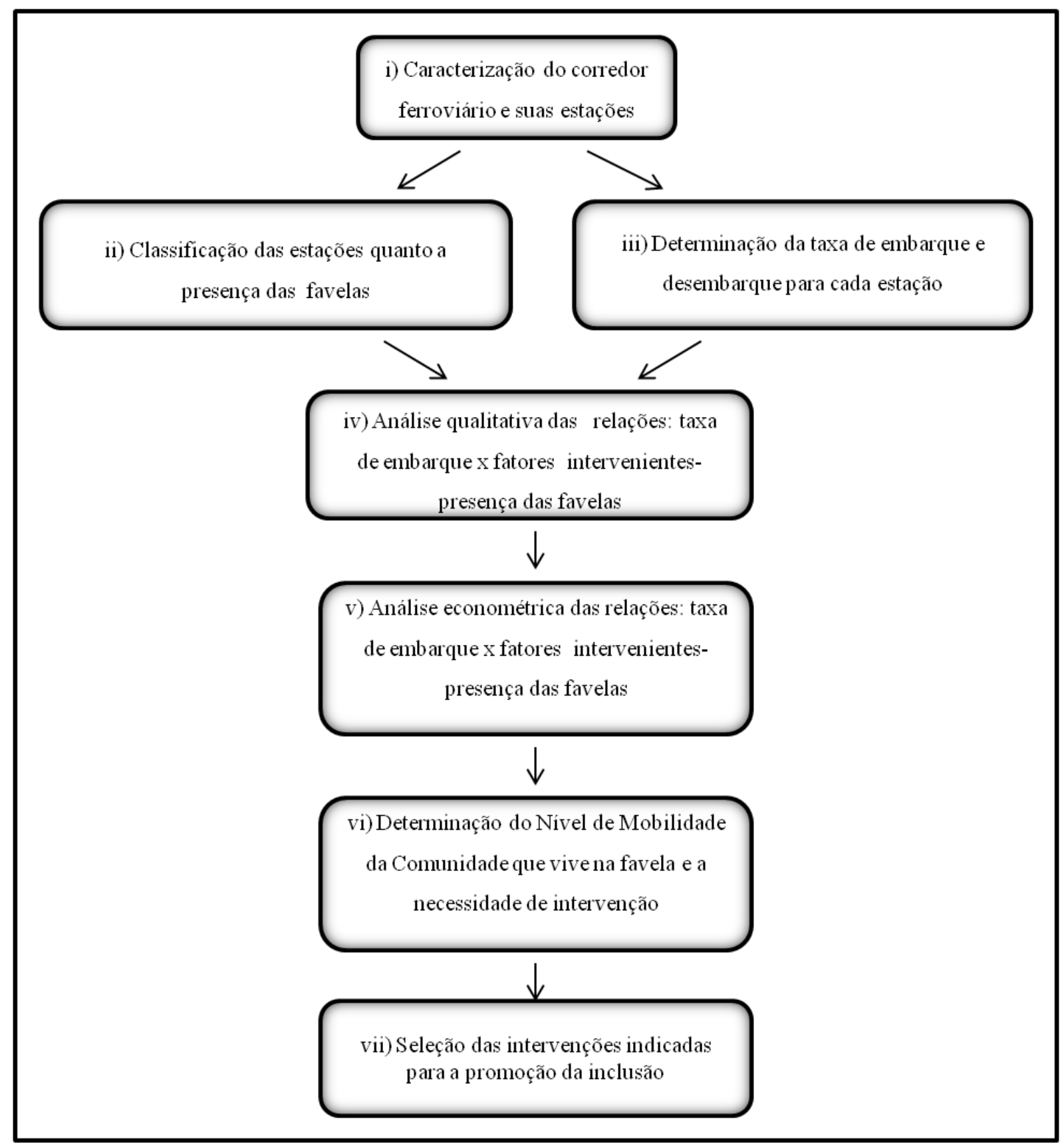

Figura 2 - Etapas para a caracterização do nível de (i)mobilidade das comunidades faveladas e as necessidades de intervenções para a promoção da inclusão.

Tal procedimento se justifica, considerando-se que, nas cidades onde o trem deu suporte ao desenvolvimento socioeconômico, o entorno das estações foi loteado e vendido à população para construção de moradias. Dessa forma, as favelas, de um modo geral, tendem a estar afastadas da estação e isoladas espacialmente das atividades urbanas, podendo causar a imobilidade (Motte-Baumvol e Nassi, 2012). Além disso, no que diz respeito à população carente que mora em favelas, em que há indícios de imobilidade, deve ser contemplado o 
isolamento espacial, nas duas escalas de acessibilidade: local e global.

$\mathrm{Na}$ escala local, uma alternativa é aplicar os conceitos oriundos do TOD e selecionar as atividades mais indicadas a serem alocadas no entorno da estação e o porte das mesmas, que podem ser inclusive um PGV, a fim de disponibilizar serviços e empregos direcionados ao atendimento das necessidades dos moradores da favela. Além de aumentar a centralidade de tal estação, tornando-a mais frequentada e estimulando o transporte não motorizado nesses deslocamentos de vizinhança. Por outro lado, o uso da estação e de seu entorno podem contribuir para melhorar a imagem do trem e torná-lo uma opção de transporte para as viagens de maior percurso.

Outra medida para combater o isolamento espacial na escala local é melhorar o acesso da comunidade da favela à estação por meio de uma maior integração com outras modalidades de menor capacidade. No caso das favelas situadas em morros, vem sendo utilizado o teleférico integrado à estação. Em qualquer situação, a construção de ciclovias e de calçadas para caminhada pode também facilitar o acesso à estação.

Além disto, é fundamental que os trens, além de uma tarifa condizente com o poder aquisitivo da população, ofereçam capacidade e qualidade suficientes para ser um meio atraente de locomoção, devendo estar conectado e integrado à rede estrutural de transportes, possibilitando desfrutar de todo o espaço urbano que reflete a acessibilidade global.

O isolamento espacial pode ser tratado considerando os cinco fatores de forma articulada e cujas soluções podem ser ampliadas gradativamente a partir da estação, chegando ao ramal e dai para toda a cidade.

O estudo articulado entre favela e trem pode convergir para a criação de um ambiente onde ações no entorno da estação incentivem o uso do trem, reduzindo o isolamento espacial e promovendo a inclusão. A oportunidade de trafegar por todo o território urbano usando o trem amplia o horizonte em termos sociais e culturais. Em contrapartida, esperava-se que isso se expresse na fidelização ao trem e seja um dos pilares da sustentabilidade do sistema ferroviário. Se os benefícios para o setor ferroviário não forem os esperados, o poder público deve intervir para garantir os ganhos sociais. 


\section{Conclusão}

A pobreza e a favela têm causas estruturais. No entanto, se pode reduzir a pobreza, atenuar o isolamento espacial e promover a inclusão social da população com base em intervenções na área urbana e no sistema de transporte. Como a favela e a estação ferroviária são Polos Geradores de Viagens, elas podem ser contempladas de forma articulada para se avaliar a existência e o nível de isolamento espacial, bem como para se contribuir na seleção das intervenções necessárias para se efetuar a inclusão social.

As intervenções podem ser elaboradas a partir da identificação dos indicadores associados aos fatores intervenientes na taxa de embarque. Portanto, conhecer tais fatores é fundamental, bem como a influência dos mesmos na geração de viagens no geral e em particular nas feitas por trem. A sistematização realizada neste trabalho aponta que alguns indicadores tendem a ter um maior relevo para explicar tal influência. Entretanto, o papel da favela nesse processo não é devidamente investigado. Um esboço de procedimento estruturado em algumas etapas proposto nesse artigo indica a possibilidade de sua aplicação em ramais existentes em cidades brasileiras, em particular daquelas com projetos de construção ou revitalização de sistemas sobre trilhos. Destaca-se, entretanto, a simplificação do modelo proposto ao assumir que a taxa de embarque nas estações expressa a mobilidade da população que vive e trabalha na área adjacente, o que nem sempre é verdade, em especial considerando a imagem atual do trem, que o torna menos atraente para uma parcela da comunidade diante de outras modalidades alternativas.

Com base na aplicação de tal procedimento, pode-se não só determinar a influência da favela na demanda por viagens por trem, bem como determinar o nível de mobilidade de seus moradores, o que é fundamental para se estabelecer a necessidade de intervenções comprometidas com a redução do isolamento espacial e a inclusão dessa comunidade. A revisão bibliográfica confirma a existência de experiências bem sucedidas em diferentes contextos, necessitando de ajustes às especificidades das favelas, o que também envolve um esforço de pesquisa, mas aponta que é possível se construir um ambiente mais integrado e menos desigual.

\section{Agradecimentos}

Ao apoio do CNPq e da Rede Ibero-Americana de Estudo em Polos Geradores de Viagens (redpgv.coppe.ufrj.br). 


\section{Referências}

Abreu, M. (2011) Evolução urbana do Rio de Janeiro. Rio de Janeiro: Editora Instituto Pereira Passos.

Anspacher, D. (2005) The demand for rail feeder shuttles. Journal of Public Transportation, vol. 8, n. 1.

Basu, D. e Hunt, J. D. (2012) Valuing of attributes influencing the attractiveness of suburban train service in Mumbai city: A stated preference approach. Transportation Reasearch Part A, vol. 46, n. 9, pp. 1465-1476.

Banco Mundial (2013) Resiliência, equidade e oportunidade, Relatório - UN.

Bertolini, L. e Spit, T. (2007). Cities on rails: the redevelopment of railway areas. Londres: Editora Milton Keynes UK: Lightning Source UK Ltd.

Brons, M. Givoni, M. e Rietveld, P. (2008) Access to railway stations and its potential in increasing rail use. Transportation Research Part A, vol. 43, n. 2, pp. 136-149.

Brown, J., Thompson, G., Bhattacharya e Jaroszynski, M. (2013) Understanding transit ridership demand for the multi-destination, multi-modal transit network in Atlanta, Georgia: lessons for increasing rail transit choice ridership while maintaining transit-dependent bus ridership. TRB Annual Meeting, Washington.

Cardoso, B. C. (2012) Um procedimento para a transferência modal do usuário do ônibus para o trem. Tese (Doutorado em Engenharia de Transporte), Universidade Federal do Rio de Janeiro, Rio de Janeiro.

Castells, M. (2009) A questão urbana. São Paulo: Editora Paz e Terra.

Cervero, R. (2011) State roles in providing affordable mass transport services for low-income residents. International Transport Forum, Leipzig.

Chu, X. (2004) Ridership models at the stop level. National Center of Transit Research. Florida: Editora National Center for Transit Researc, University of South Florida.

Comisión Económica para América Latina y el Caribe - CEPAL (2007) Panorama social de América Latina, Santiago.

Davis, M. (2006) Planeta favela. São Paulo: Bomtempo Editorial.

Debrezion, G., Pels, E. e Rietveld, P. (2009) Modelling the joint access mode and railway station choice. Transportation Research Part E, vol. 45, pp. 270-283.

Frei, C. e Mahmassani, H. S. (2013) Riding more frequently: Disaggregate ridership elasticity estimation for a large urban bus transit network. TRB Annual Meeting, Washington.

Gonçalves, J.A.M., Portugal, L. S. e Cardoso, B. C. (2012a) Estações metroferroviárias, pp. 261-286, em Polos Geradores de Viagens Orientados à qualidade de vida e ambiental: modelos e taxas de geração de viagens. Portugal, L. S. (org.). Rio de Janeiro: Editora Interciência.

Gonçalves, J. A. M., Portugal, L.S. e Nassi. C.D. (2012b) Investimentos no sistema ferroviário da Região Metropolitana do Rio de Janeiro: inclusão social e captação de usuários nas comunidades carentes, ANPET, Joinville.

Gutiérrez, O. D. C., Cardozo, O. D. e García-Palomares, J. C. (2011) Transit ridership forecasting at station level: an approach based on distance-decay weighted regression. Journal of Transport Geography, vol. 19, n.6, pp. 1081-1092 
Grieco, E., Marcolini,S., Portugal, L.S. e Soares, O. (2012) Estabelecimentos residenciais, pp. 207236, em Polos Geradores de Viagens Orientados à qualidade de vida e ambiental: modelos $e$ taxas de geração de viagens. Portugal, L. S. (org.). Rio de Janeiro: Editora Interciência.

Instituto Brasileiro de Geografia - IBGE (2010) Censo Demográfico, Brasilia.

Instituto de Pesquisa Econômica Aplicada - IPEA (2011) Dinâmica populacional e sistema de mobilidade nas metrópoles brasileiras. Comunicado Número 102, Brasília.

Instituto de Pesquisa Econômica Aplicada - IPEA (2012) Gastos das famílias das regiões metropolitanas brasileiras com transporte urbano. Comunicado Número 154, Brasília.

Institute of Transportation Engineers - ITE (2010) Parking generation, LRT.

Kuby, M., Barranda, A. e Upehurch, C. (2004) Factors influencing light-rail station boardings in the United States. Transportation Research Part A, vol. 38, n. 3, pp. 223-247.

Litman, T. (2013) Evaluating transportation equity. Victory Transpot Public Institute. Disponível em www.vtpi.org

Maricato, H. (2003) Metrópole, legislação e desigualdade. Estudos Avançados, vol. 17, n. 48.

Milovic, B. (2011) The haves and have nots. New York: Editora: Basics Books.

Ministério das Cidades (2013) Texto não publicado. Disponível em www.cidades.gov.br.

Motte-Baumvol, B. e Nassi, C. D. (2012) Immobility in Rio de Janeiro, beyond poverty. Journal of Transport Geography, vol. 24, pp. 67-76.

Pereira, L. F. (2011) Sistema ferroviário e Pólos Geradores de Viagens: Implicações na centralidade local. Rede Íbero-Americana de Estudos em Pólos Geradores de Viagens. Disponível em redpgv.coppe.ufrj.br.

Pereira, R. H. M. e Schwanen, T. (2013) Tempo de deslocamento casa-trabalho no Brasil (1992-2009): Diferenças entre Regiões Metropolitanas, Níveis de Renda e Sexo, IPEA.

Portugal, L. S., Floréz, J. e Silva, A. N. R. (2010) Rede de pesquisa em transportes: um instrumento de transformação e melhora da qualidade de vida. Transportes, vol. 18, n. 1, pp. 6-16.

Portugal, L. S. (2012) Polos Geradores de Viagens orientados à qualidade de vida e ambiental: modelos e taxas de geração de viagens. Rio de Janeiro: Editora Interciência.

Portal Brasil (2013) Notícias. Disponível em www.brasil.gov.br.

Quade, B. P. e Douglas, I. (1996) Transit and urban form, TCRP Report 16, vol. 1. Washington: Editora National Academy.

Reusser, D., E., Loukopoulos, P., Stauffacher, M. e Scholz, R., W. (2008) Classifying railway stations for sustainable transitions - balancing node and place functions. Journal of Transport Geography, vol. 16, pp. 191-202.

Sánches, F. e Moura, R. (2005) Ciudades-modelo: estrategias convergentes para su difusión internacional. Revista Eure, vol. 31, n. 93, pp. 21-34.

Secretaria de Estadual de Transporte SECTRAN (2011) Programa estadual de transportes II, Governo do Estado do Rio de Janeiro.

Secretaria Nacional de Transporte e Mobilidade Urbana (2007) Guia PlanMob, Ministério das Cidades, Brasil.

Sohn, K. e Shim, H. (2010) Factors generating boarding at Metro stations in the Seoul metropolitan area. Cities, vol. 27, pp. 358-368.

Suzuki, H., Cervero, R. e Luchi, K. (2013) Transformacion de las ciudades mediante el transporte público. Banco Mundial. 
Walters, G. e Cervero, R. (2003). Forecasting Transit Demand in a Fast Growing Corridor: The Direct-Ridership Model Approach. Technical Memorandum prepared for the Bay Area Rapid Transit District. Lafayette: Fehr and Peers.

Zemp, S., Stauffacher, M., Lang., D., J. e Scholz, R. W. (2010) Classifying railway stations for strategic transport and land use planning: context matters, Journal of Transport Geograph. vol. 19 n. 4 pp. 670-679. 